Case Report

\title{
Left Functional Pneumonectomy Caused by a Very Rare Giant Intrathoracic Cystic Lesion in a Patient with Gorham-Stout Syndrome: Case Report and Review of the Literature
}

\author{
Nikolaos Tasis $\mathbb{D}^{\mathbb{D}},{ }^{1}$ Ioannis Tsouknidas, ${ }^{1}$ Argyrios Ioannidis $\left(\mathbb{D},{ }^{1}\right.$ \\ Konstantinos Nassiopoulos, ${ }^{2}$ and Dimitrios Filippou $\mathbb{D}^{1,3}$ \\ ${ }^{1}$ Department of Anatomy and Surgical Anatomy, Medical School, National and Kapodistrian University of Athens, Athens, Greece \\ ${ }^{2}$ Hopital Daler, Fribourg, Switzerland \\ ${ }^{3}$ Department of Surgical Oncology, Laparoscopic Surgery and Laser Surgery, N Athinaio Hospital, Athens, Greece
}

Correspondence should be addressed to Nikolaos Tasis; tasisnikolaos@gmail.com

Received 14 December 2017; Accepted 18 February 2018; Published 12 April 2018

Academic Editor: Tun-Chieh Chen

Copyright ( 2018 Nikolaos Tasis et al. This is an open access article distributed under the Creative Commons Attribution License, which permits unrestricted use, distribution, and reproduction in any medium, provided the original work is properly cited.

Gorham-Stout syndrome is an uncommon entity, with few cases reported in bibliography. It consists of osteolytic manifestations affecting various bones and replacing them with lymphangiomatous tissue. With pathophysiology unknown, Gorham-Stout disease affects also cardiorespiratory system usually causing lytic lesions to the bones of the thoracic cage or directly invading the thoracic duct. This is a case report of a unique respiratory manifestation of the disease and a review of its cardiorespiratory complications.

\section{Introduction}

Gorham-Stout syndrome or vanishing bone disease is a rare entity with very few cases reported in global bibliography. Gorham et al. in 1954 [1] and Gorham and Stout in 1955 [2] firstly described this uncommon form of massive osteolysis. Till today, etiology and pathophysiology of the disease are unknown. The syndrome consists of replacement of normal bone by nonneoplastic vascular tissue, via overgrowth of lymphatic vessels, resulting in an "invisible" hypervascular fibrous bone [3]. The prognosis varies, with some patients achieving stabilization, while others, especially if complicated with pleural effusion, showing high mortality rates [4]. We present a case report of a unique thoracic presentation of Gorham-Stout syndrome and a detailed review of the literature concerning respiratory manifestations and complications of the disease.

\section{Case Presentation}

In 1997, female patient, 24 years old, presented intense lower back pain. Lumbar spine CT revealed multiple osteolytic lesions in lumbar vertebrae. Further investigation by attending physicians ruled out neoplastic infiltration. Clinical and laboratory exams were normal, except for slightly decreased calcium levels of unknown origin, with normal levels of PTH, so the patient was treated conservatively with NSAIDs and careful medical advice.

In May of 2004, the patient discovered a nodule in left thyroid lobe, which gradually increased in size. Biopsy revealed follicular thyroid cancer, and a total thyroidectomy was performed. Histological exam showed papillary and follicular thyroid cancer. Histological preparation did not consist of any parathyroid gland, although patient suffered from severe hypocalcaemia for many years postoperatively until utterly controlled by attending endocrinologist with administration of calcium and salmon calcitonin. In September of 2004, a large cystic mass was detected in anterior cervical surface, left of the clavicle. Ultrasound revealed a cyst with $4 \mathrm{~cm}$ diameter which was surgically removed. Histological exam suggested lymphatic cyst.

In 2007, a relapse was observed and was US monitored for the next months. In 2008, the patient was referred to our department for further investigation. Clinical examination 
showed the palpable mass in the lower anterior section of the cervix, with $3 \mathrm{~cm}$ diameter, increasing in size. Lab tests were normal apart from CPK (250 IU/L), serum phosphorus $(5,6 \mathrm{mg} / \mathrm{dl})$, and serum calcium $(7,8 \mathrm{mg} / \mathrm{dl})$. Thoracic and Cervical MRI reveal a substantial cystic mass $(12,5 \times 2,2 \times$ $2,3 \mathrm{~cm}$ ) in anterior mesothorax. Two similar masses were detected one paratracheal $(2,6 \times 4 \mathrm{~cm})$ and one in the lower cervix $(2,4 \times 2 \mathrm{~cm})$, all communicating. Lower and upper abdomen CT showed multiple cystic lesions of the spleen, while full MRI check revealed no change in cystic lesions of lumbar vertebrae, with several similar lesions in whole vertebrae column, the clavicle and both femurs. FNA procedure took place and the sample proved to be lymph. FNA in combination with CT and MRI results indicated Gorham-Stout disease.

Patient continued receiving conservative therapy with calcium and salmon calcitonin and after six months calcium levels became normal and bone density reached normal range, improving by far patient's quality of life. Mesothorax and spinal cystic lesions were reevaluated regularly and no change in size was noted.

The next two years patient underwent two incidents which were impossible to properly diagnose. The first consisted of an intense headache, which lasted for 15 days during patient's vacation, with following improvement and the second involved a vision disorder which was examined by an ophthalmologist with no pathology defined.

However, in 2010, the patient was admitted due to intense headache, gradually increasing, affecting patient's quality of life. Although examination revealed no abnormal findings, the patient was deteriorating. A lumbar puncture took place and showed low cerebrospinal fluid (CSF) pressure $(<6)$. Intravenous fluids were administrated and, later, patient improved and was discharged, only to come two days later with severe temporal and cervical cephalalgia and vertigo. Otorhinolaryngological examination was not pathological and patient was treated conservatively with Sibellium, Lonarid-N, and Tramal tablets. Patient improved but further examination took place. Full-body 3D CT scan with intrathecal radioactive polymer infusion revealed the following: (1) incomplete herniation of the brain stem probably due to low CSF pressure; (2) dilation of endothoracic cyst, with more than $20 \mathrm{~cm}$ diameter, fully compressing left lung causing functional left pneumonectomy; and (3) possible communication of CSF with mesothoracic cystic mass (Figures 1(a), $1(\mathrm{~b})$, and 2).

Surgical excision was undertaken. Patient underwent thoracoscopic excision of the gargantuan cystic mass, with ligation of major lymph vessels, conserving major thoracic duct. No connection between the cyst and spinal cavity was detected, possibly because during the excision procedure the connection was ligated or shut. Patient had a smooth postoperative course and recovery.

\section{Discussion}

Gorham-Stout syndrome (GSS), also known as Gorham's syndrome, idiopathic massive osteolysis, disappearing bone, disease or phantom bone disease, is a rare skeletal disorder, characterized by osteolysis of various bones accompanied by proliferative angiomatosis. Almost 180 years have passed since Jackson first presented, in 1838, the case of an 18year-old boy with idiopathic osteolysis of his right humerus [62]. In 1955, Gorham and Stout, after concentrating and studying all previous similar cases, described "a syndrome of progressive osteolysis associated with an angiomatosis proliferation of blood or lymphatic vessels" [2]. Although over 200 cases have been reported to date [63], there is still a lot to learn about this syndrome.

Gorham-Stout syndrome provokes osteolytic damage to one or multiple bones. It can affect any age, but most commonly children and young adults. Special correlation with specific race, sex, geography, or hereditary pattern has not been identified yet [64]. The shoulder and the pelvis are the most common sites to be affected according to Patel [3]. Femur as more possible first presentation is described by Ruggieri et al. [65] and Hu et al. [66]. Cases of phantom bone disease to the skull, mandible, maxillofacial skeleton, spine, scapula, clavicle, ribs, sternum, humerus, hand, and foot have also been described [3]. In our case lumbar osteolytic lesions may be considered the first sign of Gorham-Stout syndrome. Our patient experienced intense low back pain at the age of 22. The symptom was treated as common back pain and although lesions of lumbar spine were detected, no further investigation was required since neoplastic etiology was ruled out and laboratory tests were normal. Pain was relieved with NSAIDs and the patient continued everyday activity without symptoms for years. Pain is considered to be a frequent atypical symptom of GSS [64], mainly because of lymphangiomatous infiltration of bones. Maillot et al. [67] state that vertebral primary involvement is rare $(10 \%)$ and associated with a poor prognosis. However, patients tend to be undiagnosed until pathological fracture takes place even if localized pain is present [65]. The fact that Gorham-Stout progression may be asymptomatic reinforces our belief of lumbar spine involvement in our case.

In the course of the case, two years after thyroidectomy, a cystic mass was spotted in lower anterior cervix of the patient. It was identified as a lymphangiomatous cyst and was surgically excised. Six months later, a relapse caused the referral of the patient to our department only to diagnose one large mesothoracic cyst $(12,5 \times 2,2 \times 2,3 \mathrm{~cm})$ with two smaller and one paratracheal $(2,6 \times 4 \mathrm{~cm})$ cysts and one in the lower cervix $(2,4 \times 2 \mathrm{~cm})$. In addition, osteolytic lymphangiomatous lesions, common Gorham-Stout syndrome's manifestations [64], were located in whole vertebrae column, the clavicle, and both femurs as well as in spleen. Patient was treated conservatively with calcitonin and regularly checked. Cysts were monitored and there was no change in size until patient had a thorough investigation for intense cephalalgia. Only then did we come across a unique finding. CT revealed dilation of endothoracic cyst, more than $20 \mathrm{~cm}$ in diameter, fully compressing left lung causing functional left pneumonectomy. Also, there was incomplete herniation of the brain stem due to low CSF pressure, probably because of possible communication of CSF with mesothoracic cystic mass, which could not be verified thoracoscopically. 


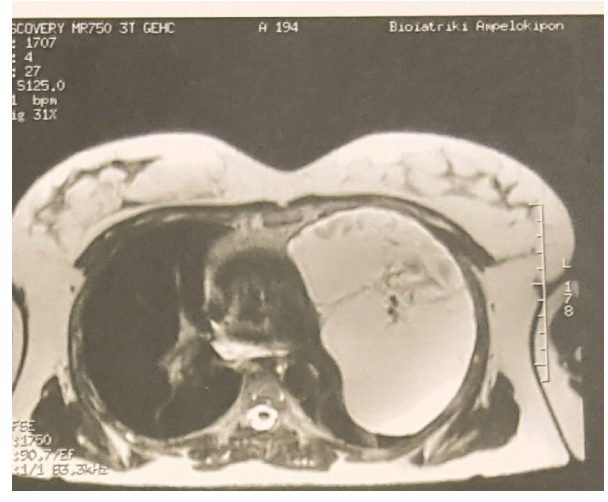

(a)

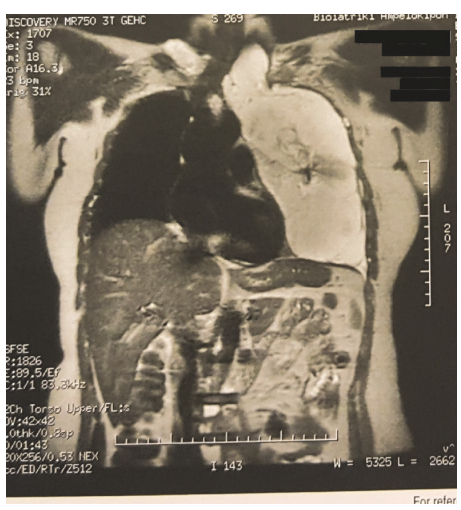

(b)

FIGURE 1: A giant cystic lesion occupying almost completely the left side of thorax causing functional pneumonectomy.

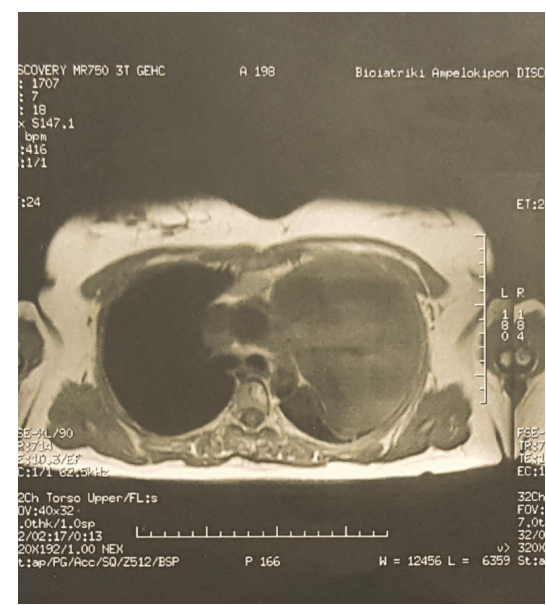

FIGURE 2: MRI of the intrathoracic cystic lesion. Osteolytic lesion in the thoracic vertebrae also obvious.

Disease of the bones of the thoracic cage often presents with pleural effusion and/or chylothorax. Chylothorax is present up to $17 \%$ of the patients [50] and increases the rate of mortality and morbidity, especially if patients do not undergo surgical intervention [68]. There are 67 confirmed cases of Gorham-Stout syndrome with cardiorespiratory invasion found in the literature (Table 1). Chylothorax was present in 60 of them $(89,55 \%)$ and was the major presenting symptom in the thorax. In literature we found, also, two cases of nondescript pleural effusion [4, 56], one case of hemothorax [29], one case with hematoma [29], and three cases with bloody pleural effusion $[32,34,47]$. One unusual case of duropleural fistula [47] was noted as well. Concerning more rare cardiac presentations, there were two cases with chylotamponade $[41,52]$, one with hemochylopericardium [46], and two cases of nondescript pericardial effusion $[4,44]$ reported in literature. In these 67 cases we only encountered 2 cases of lymphangiomatous cysts [37,61], one in the mediastinum and one located in right anterior chest wall. Our case is the third with cystic presentation of Gorham-Stout syndrome. However, the fact that the massive lymphangiomatous cyst provoked a functional left pneumonectomy due to its size and position in the mesothorax has not been described previously in Gorham-Stout disease. Usually, the cysts are found and dealt with at early stages or erupt into the pleural cavity causing chylothorax. In this case the cyst reached $20 \mathrm{~cm}$ in diameter, caused left functional pneumonectomy, and was identified randomly after CT scan. Our patient underwent surgery and had an uncomplicated recovery. Mortality in Gorham-Stout disease with thoracic cage presentation as reported in the literature is high. Out of 67 cases, 22 did not survive $(32,8 \%)$. Surgical ligation, pleurodesis, and other surgical or radiological treatments seem to improve survival for patients with these complications [68].

\section{Conclusion}

Gorham-Stout syndrome is an uncommon condition. With etiology unknown, diagnosis and treatment remain a challenge. Osteolytic lesions and/or pathological fractures should raise clinical suspicion for GSS. Attention is needed, especially when respiratory complications are present. This case offers a new presentation of the disease and along with past and future cases may contribute to a deeper understanding 


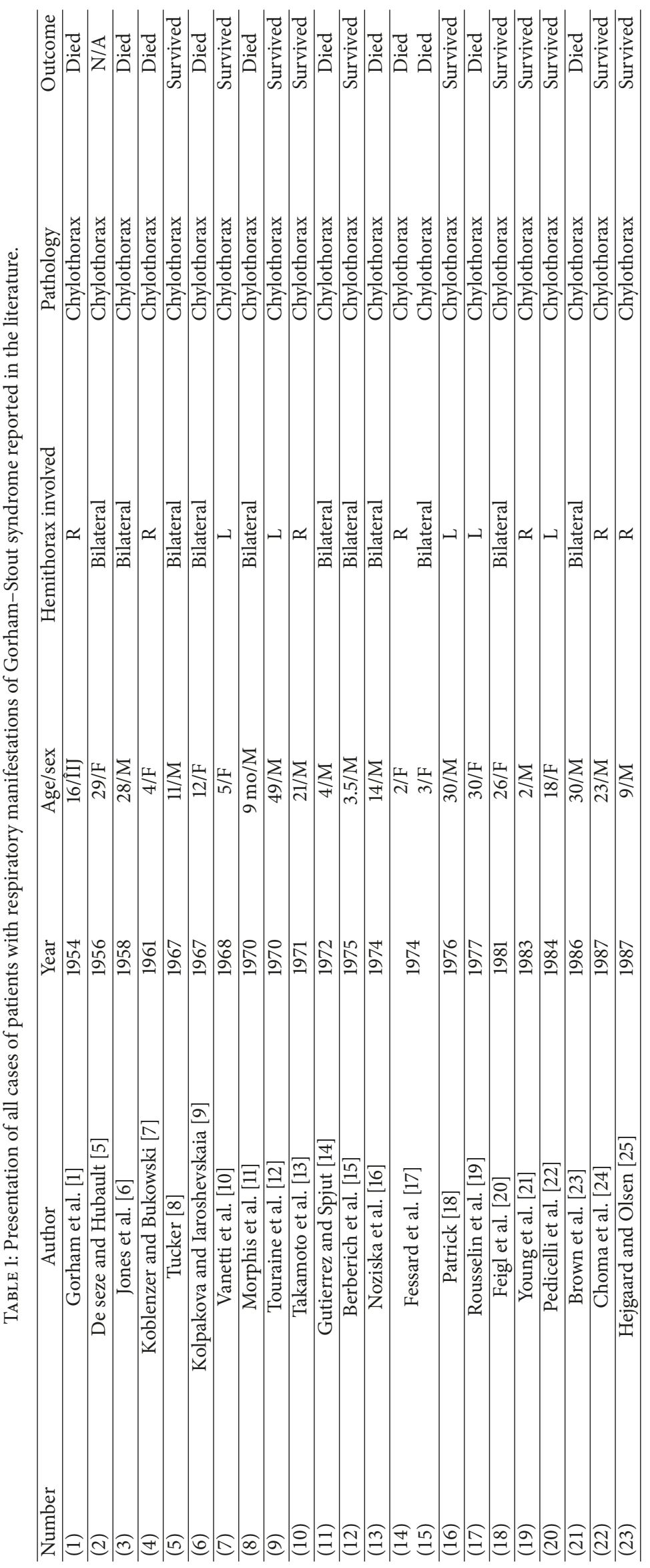




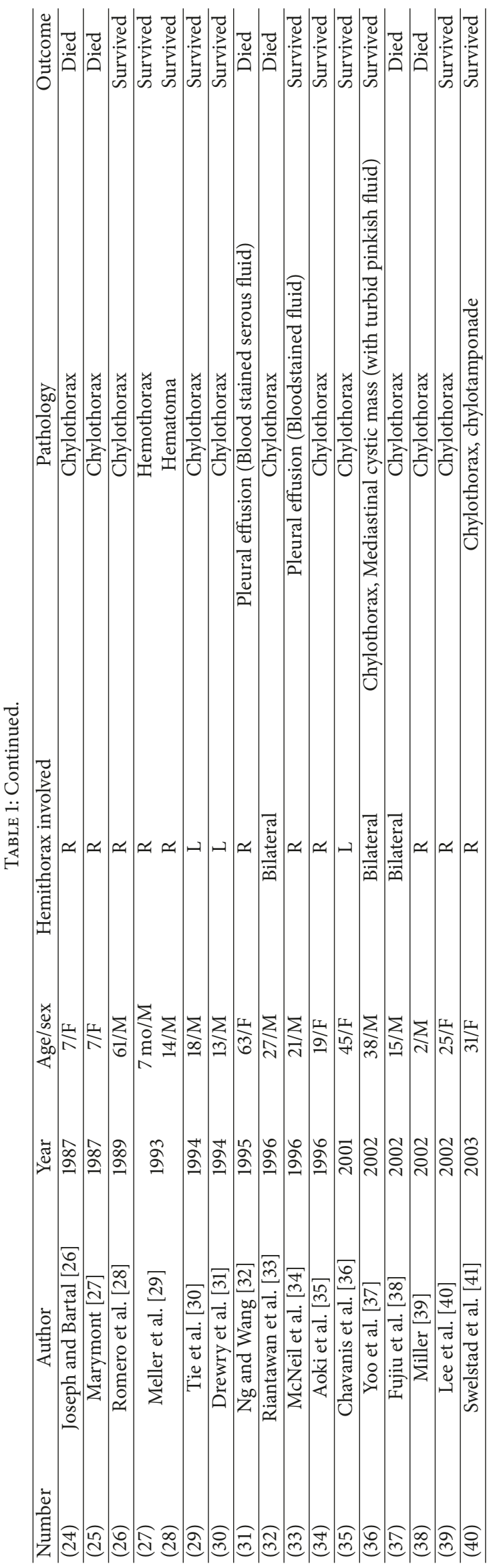




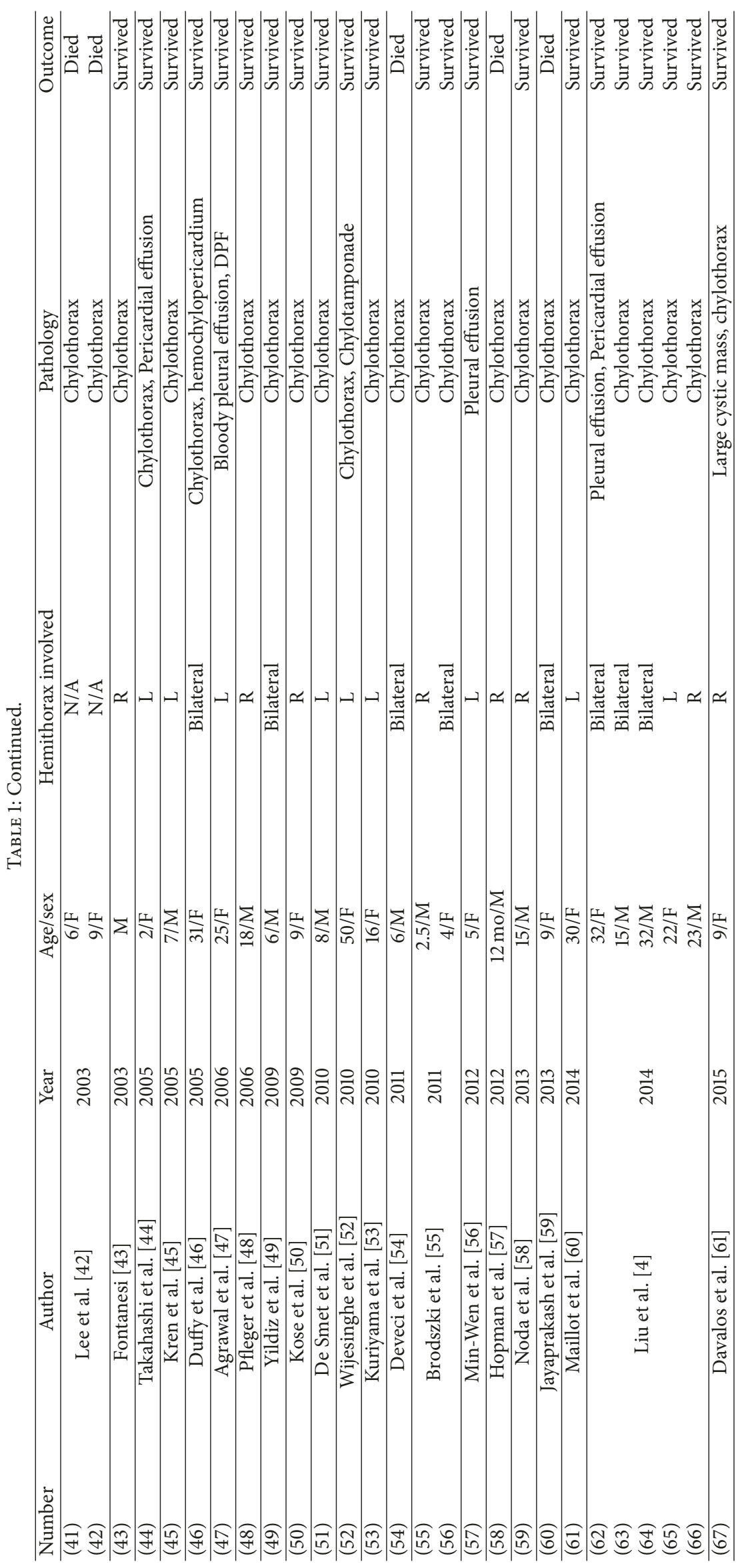


of this extraordinary clinical entity, the Gorham-Stout Syndrome.

\section{Consent}

Written consent of the patient was obtained for publication.

\section{Conflicts of Interest}

The authors declare no conflicts of interest.

\section{References}

[1] L. W. Gorham, A. W. Wright, H. H. Shultz, and F. C. Maxon Jr., "Disappearing bones: A rare form of massive osteolysis. Report of two cases, one with autopsy findings," American Journal of Medicine, vol. 17, no. 5, pp. 674-682, 1954.

[2] L. W. Gorham and A. P. Stout, "Massive osteolysis (Acute spontaneous absorption of bone, phantom bone, disappearing bone)," The Journal of Bone \& Joint Surgery, vol. 37, no. 5, pp. 985-1004, 1955.

[3] D. V. Patel, "Gorham's Disease or Massive Osteolysis," Clinical Medicine \& Research, vol. 3, no. 2, pp. 65-74, 2005.

[4] Y. Liu, D.-R. Zhong, P.-R. Zhou et al., "Gorham-Stout disease: radiological, histological, and clinical features of 12 cases and review of literature," Clinical Rheumatology, vol. 35, no. 3, pp. 813-823, 2016.

[5] S. De seze and A. Hubault, "Essential osteolysis scapulothoraco-brachial," Revue du Rhumatisme et des Maladies OsteoArticulaires, vol. 23, no. 6, pp. 517-523, 1956.

[6] G. B. Jones, R. L. Midgley, G. S. Smith et al., "Massive osteolysisdisappearing bones," The Journal of Bone and Joint Surgery, pp. 40B-494, 1958.

[7] P. G. Koblenzer and M. J. Bukowski, "Angiomatosis (Hamartomatosis-Hem-Lymphangiomatosis). Report of a case with diffuse involvement," Pediatrics, vol. 28, p. 65, 1961.

[8] S. M. Tucker, "Bilateral chylothorax with multiple osteolytic lesions? Generalized abnormality of lymphatic system," Proceedings of the Royal Society of Medicine, vol. 60, no. 1, pp. 17-19, 1967.

[9] L. V. Kolpakova and E. N. Iaroshevskaia, "A case of massive regional osteolysis," Arkh Patol, vol. 29, no. 5, pp. 75-77, 1967.

[10] A. Vanetti, J. D. Picard, M. Fandre et al., "A case of apparently spontaneous chylothorax in children associated with osseous lesions of the osteolytic type," Annales de chirurgie thoracique et cardio-vasculaire, vol. 7, no. 1, pp. 99-104, 1968.

[11] L. G. Morphis, E. L. Arcinue, and J. R. Krause, "Generalized lymphangioma in infancy with chylothorax," Pediatrics, vol. 46, no. 4, pp. 566-575, 1970.

[12] R. Touraine, J. P. Trouillier, and A. M. Balander, "Chylothorax et maladie de Gorham," Lyon Med, vol. 224, pp. 445-466, 1970.

[13] R. M. Takamoto, R. G. Armstrong, W. Stanford, L. J. Fontenelle, and G. Troxler, "Chylothorax with multiple lymphangiomata of the bone.," CHEST, vol. 59, no. 6, pp. 687-689, 1971.

[14] R. M. Gutierrez and H. J. Spjut, "Skeletal angiomatosis: report of three cases and review of the literature.," Clinical Orthopaedics and Related Research, vol. 85, pp. 82-97, 1972.

[15] F. R. Berberich, I. D. Bernstein, H. D. Ochs, and R. T. Schaller, "Lymphangiomatosis with chylothorax," Journal of Pediatrics, vol. 87 , no. 6 , pp. 941-943, 1975.
[16] Z. Nozicka, V. Herout, and Fingerland A., "Gorhauv-Stoutuv syndrome zpusobeny hemangio-lymfangiomen," Czech Patol, vol. 10, pp. 56-62, 1974.

[17] C. I. Fessard, C. Boulesteix, C. H. Roudil, N. Grynblat, A. Fondimare, R. Dumas et al., "ascite chyleuse, chylothorax et ectasiescapillares intra-osseuses," Arch Fr Pediatr, vol. 31, pp. 489-506, 1974.

[18] J. H. Patrick, "Massive osteolysis complicated by chylothorax successfully treated by pleurodesis," The Journal of Bone \& Joint Surgery (British Volume), vol. 58, no. 3, pp. 347-349, 1976.

[19] L. Rousselin, G. Roche, and M. F. Carette, "Les epanchements pleuraux (chyleux ou non) avec osteolyse regionale," Le Poumon et le Coeur, vol. 3, pp. 203-207, 1977.

[20] D. Feigl, L. Seidel, and A. Marmor, "Gorham's disease of the clavicle with bilateral pleural effusions," CHEST, vol. 79, no. 2, pp. 242-244, 1981.

[21] J. W. R. Young, M. Galbraith, J. Cunningham et al., "Case report: Progressive vertebral collapse in diffuse angiomatosis," Metabolic Bone Disease and Related Research, vol. 5, no. 2, pp. 53-60, 1983.

[22] G. Pedicelli, P. Mattia, A. A. Zorzoli, A. Sorrone, F. De Martino, and V. Sciotto, "Gorham syndrome," Journal of the American Medical Association, vol. 252, no. 11, pp. 1449-1451, 1984.

[23] L. R. Brown, H. M. Reiman, E. C. Rosenow III, P. M. Gloviczki, and M. B. Divertie, "Intrathoracic lymphangioma," Mayo Clinic Proceedings, vol. 61, no. 11, pp. 882-892, 1986.

[24] N. D. Choma, C. V. Biscotti, T. W. Bauer, A. C. Mehta, and A. A. Licata, "Gorham's syndrome: A case report and review of the literature," American Journal of Medicine, vol. 83, no. 6, pp. 11511156, 1987.

[25] N. Hejgaard and P. R. Olsen, "Massive gorham osteolysis of the right hemipelvis complicated by chylothorax: Report of a case in a 9-year-old boy successfully treated by pleurodesis," Journal of Pediatric Orthopaedics, vol. 7, no. 1, pp. 96-99, 1987.

[26] J. Joseph and E. Bartal, "Disappearing bone disease: A case report and review of the literature," Journal of Pediatric Orthopaedics, vol. 7, no. 5, pp. 584-588, 1987.

[27] J. V. Marymont, "Comparative imaging. Massive osteolysis (Gorham's syndrome, disappearing bone disease)," Clinical Nuclear Medicine, vol. 12, no. 2, pp. 153-154, 1987.

[28] J. Romero, R. Kunz, U. Münch, and U. Neff, "Successful treatment of a chylothorax in lymphangiomatosis of the ribs (Gorham-Stout syndrome)," Schweiz Med Wochenschr, vol. 119, no. 20, pp. 671-677, 1989.

[29] J. L. Meller, M. Curet-Scott, P. Dawson, A. S. Besser, and D. W. Shermeta, "Massive osteolysis of the chest in children: An unusual cause of respiratory distress," Journal of Pediatric Surgery, vol. 28, no. 12, pp. 1539-1542, 1993.

[30] M. L. H. Tie, G. A. Poland, and E. C. Rosenow III, "Chylothorax in Gorham's syndrome: A common complication of a rare disease," CHEST, vol. 105, no. 1, pp. 208-213, 1994.

[31] G. R. Drewry, C. R. Martinez, and S. G. Brantley, "Gorham disease of the spine," The Spine Journal, vol. 19, no. 19, pp. 22132222, 1994.

[32] S. E. S. Ng and Y. T. Wang, "Gorhams syndrome with pleural effusion and colonic carcinoma," Singapore Medical Journal, vol. 36, pp. 102-104, 1995.

[33] P. Riantawan, S. Tansupasawasdikul, and P. Subhannachart, "Bilateral chylothorax complicating massive osteolysis (Gorham's syndrome)," Thorax, vol. 51, no. 12, pp. 1277-1278, 1996. 
[34] K. D. McNeil, K. M. Fong, Q. J. Walker, P. Jessup, and P. V. Zimmerman, "Gorham's syndrome: A usually fatal cause of pleural effusion treated successfully with radiotherapy," Thorax, vol. 51, no. 12, pp. 1275-1276, 1996.

[35] M. Aoki, F. Kato, H. Saito, K. Mimatsu, and H. Iwata, "Successful treatment of chylothorax by bleomycin for Gorham's disease," Clinical Orthopaedics and Related Research, no. 330, pp. 193-197, 1996.

[36] N. Chavanis, P. Chaffanjon, G. Frey, G. Vottero, and P.-Y. Brichon, "Chylothorax complicating Gorham's disease," The Annals of Thoracic Surgery, vol. 72, no. 3, pp. 937-939, 2001.

[37] S. Y. Yoo, J. M. Goo, and J.-G. Im, "Mediastinal Lymphangioma and Chylothorax: Thoracic Involvement of Gorham's Disease," Korean Journal of Radiology, vol. 3, no. 2, pp. 130-132, 2002.

[38] K. Fujiu, R. Kanno, H. Suzuki, N. Nakamura, and M. Gotoh, "Chyothorax associated with massive osteolysis (Gorham's syndrome)," The Annals of Thoracic Surgery, vol. 73, no. 6, pp. 19561957, 2002.

[39] G. Miller, "Treatment of chylothorax in Gorhams disease: case report and literature review," Canadian Journal of Surgery, vol. 45, no. 4, 2002.

[40] W. S. Lee, S. H. Kim, I. Kim et al., "Chylothorax in Gorham's disease," Journal of Korean Medical Science, vol. 17, no. 6, pp. 826-829, 2002.

[41] M. R. Swelstad, C. Frumiento, A. Garry-McCoy, R. Agni, and T. L. Weigel, "Chylotamponade: An unusual presentation of Gorham's Syndrome," The Annals of Thoracic Surgery, vol. 75, no. 5, pp. 1650-1652, 2003.

[42] S. Lee, L. Finn, R. W. Sze, J. A. Perkins, and K. C. Sie, “Gorham Stout Syndrome (Disappearing Bone Disease): Two Additional Case Reports and a Review of the Literature," Archives of Otolaryngology-Head and Neck Surgery, vol. 129, no. 12, pp. 1340-1343, 2003.

[43] J. Fontanesi, "Radiation therapy in the treatment of Gorham disease," Journal of Pediatric Hematology/Oncology, vol. 25, no. 10, pp. 816-817, 2003.

[44] A. Takahashi, C. Ogawa, T. Kanazawa et al., "Remission induced by interferon alfa in a patient with massive osteolysis and extension of lymph-hemangiomatosis: A severe case of GorhamStout syndrome," Journal of Pediatric Surgery, vol. 40, no. 3, pp. E47-E50, 2005.

[45] L. Kren, P. Rotterova, M. Hermanova et al., "Chylothorax as a possible diagnostic pitfall: A report of 2 cases with cytologic findings," Acta Cytologica, vol. 49, no. 4, pp. 441-444, 2005.

[46] B. Duffy, R. Manon, R. Patel, and J. Welsh, "A Case of gorhams disease with chylothorax treated curatively with radiation therapy," $C M$ \& $R$, vol. 3, no. 2, pp. 83-86, 2005.

[47] R. Agrawal, I. Mohammed, and P. G. Reilly, "Duropleural fistula as a consequence of Gorham-Stout syndrome: A combination of 2 rare conditions," The Journal of Thoracic and Cardiovascular Surgery, vol. 131, no. 5, pp. 1205-1206, 2006.

[48] A. Pfleger, W. Schwinger, A. Maier, J. Tauss, H. H. Popper, and M. S. Zach, "Gorham-Stout syndrome in a male adolescent Case report and review of the literature," Journal of Pediatric Hematology/Oncology, vol. 28, no. 4, pp. 231-233, 2006.

[49] T. S. Yildiz, A. Kus, M. Solak, and K. Toker, "The Gorham-Stout syndrome: One lung ventilation with a bronchial blocker. A case of Gorham's disease with chylothorax," Pediatric Anesthesia, vol. 19, no. 2, pp. 190-191, 2009.

[50] M. Kose, S. Pekcan, D. Dogru et al., "Gorham-Stout syndrome with chylothorax: Successful remission by interferon alpha-2b," Pediatric Pulmonology, vol. 44, no. 6, pp. 613-615, 2009.
[51] K. De Smet, M. De Maeseneer, E. Huijssen-Huisman, V. Van Gorp, S. Hachimi-Idrissi, and C. Ernst, "A rare cause of dyspnea due to chylothorax," Emergency Radiology, vol. 17, no. 6, pp. 503$505,2010$.

[52] N. Wijesinghe, Z. Lin, M. J. Swarbrick, and D. M. Jogia, "Chylotamponade an unusual manifestation of gorham-stout syndrome," Circulation: Cardiovascular Imaging, vol. 3, no. 2, pp. 223-224, 2010.

[53] D. K. Kuriyama, S. C. McElligott, D. W. Glaser, and K. S. Thompson, "Treatment of gorham-stout disease with zoledronic acid and interferon- $\alpha$ : A case report and literature review," Journal of Pediatric Hematology/Oncology, vol. 32, no. 8, pp. 579-584, 2010.

[54] M. Deveci, N. Inan, F. Çorapçioğlu, and G. Ekingen, "GorhamStout syndrome with chylothorax in a six-year-old boy," The Indian Journal of Pediatrics, vol. 78, no. 6, pp. 737-739, 2011.

[55] N. Brodszki, J.-K. Länsberg, M. Dictor et al., "A novel treatment approach for paediatric Gorham-Stout syndrome with chylothorax," Acta Paediatrica, vol. 100, no. 11, pp. 1448-1453, 2011.

[56] Z. Min-Wen, M. Yang, Q. Jian-Xin et al., "Gorham-stout syndrome presenting in a 5-year-old girl with a successful bisphosphonate therapeutic effect," Experimental and Therapeutic Medicine, vol. 4, no. 3, pp. 449-451, 2012.

[57] S. M. J. Hopman, R. R. Van Rijn, C. Eng et al., "PTEN hamartoma tumor syndrome and Gorham-Stout phenomenon," American Journal of Medical Genetics Part A, vol. 158, no. 7, pp. 1719-1723, 2012.

[58] M. Noda, C. Endo, Y. Hoshikawa et al., "Successful management of intractable chylothorax in Gorham-Stout disease by awake thoracoscopic surgery," General Thoracic and Cardiovascular Surgery, vol. 61, no. 6, pp. 356-358, 2013.

[59] B. Jayaprakash, B. Prajeesh, and D. S. Nair, "Gorham's Disease," The Journal of the Association of Physicians of India, vol. 61, 2013.

[60] C. Maillot, T. Cloche, and J. C. Le Huec, “Thoracic osteotomy for Gorham-Stout disease of the spine: a case report and literature review," European Spine Journal, 2014.

[61] E. A. Davalos, N. M. Gandhi, D. Barank, and R. K. Varma, "Gorham-stout disease presenting with dyspnea and bone pain in a 9-year-old girl," Radiology Case Reports, vol. 10, no. 2, p. 1110, 2015.

[62] J. B. S. Jackson, “A Boneless Arm," The Boston Medical and Surgical Journal, vol. 18, pp. 368-369, 1838.

[63] U. Brunner, K. Rückl, C. Konrads, M. Rudert, and P. Plumhoff, "Gorham-Stout syndrome of the shoulder," SICOT-J from Société Internationale de Chirurgie Orthopédique et de Traumatologie, vol. 2, no. 25, pp. 1-7, 2016.

[64] V. S. Nikolaou, D. Chytas, D. Korres, and N. Efstathopoulos, "Vanishing bone disease (gorham-stout syndrome): A review of a rare entity," World Journal of Orthopedics, vol. 5, no. 5, pp. 694698, 2014.

[65] P. Ruggieri, M. Montalti, A. Angelini, M. Alberghini, and M. Mercuri, "Gorham-Stout disease: The experience of the Rizzoli Institute and review of the literature," Skeletal Radiology, vol. 40, no. 11, pp. 1391-1397, 2011.

[66] P. Hu, X. Yua, X. Hu, F. Shen, and J. Wang, "Gorham-Stout syndrome in mainland China: a case series of 67 patients and review of the literature," J Zhejiang Univ-Sci B (Biomed \& Biotechnol), vol. 14, no. 8, pp. 729-735, 2013. 
[67] C. Maillot, T. Cloche, and J.-C. Le Huec, "Thoracic osteotomy for Gorham-Stout disease of the spine: a case report and literature review," European Spine Journal, 2014.

[68] S. M. Gondivkar and A. R. Gadbail, "Gorham-Stout syndrome: a rare clinical entity and review of literature," Oral Surgery, Oral Medicine, Oral Pathology, Oral Radiology, and Endodontology, vol. 109, no. 2, pp. e41-e48, 2010. 


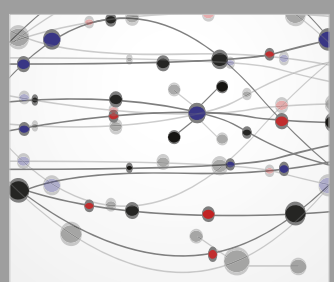

The Scientific World Journal
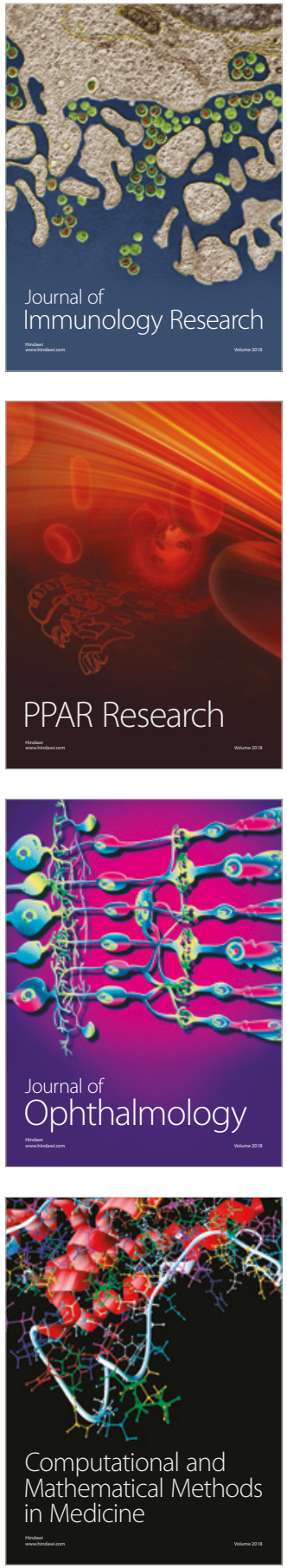

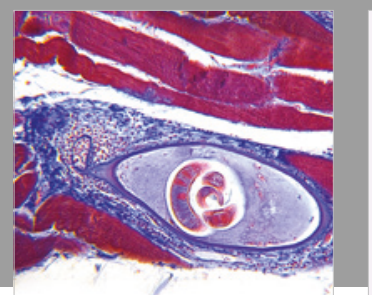

Gastroenterology Research and Practice

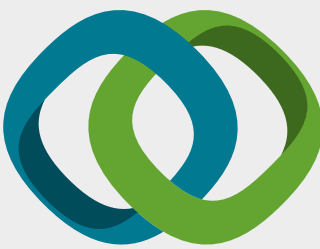

\section{Hindawi}

Submit your manuscripts at

www.hindawi.com
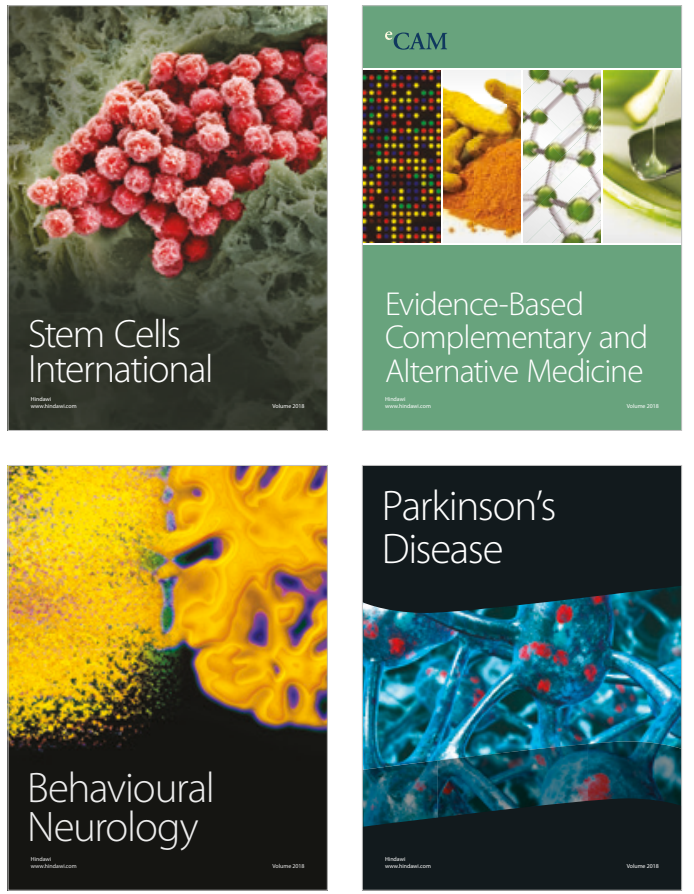

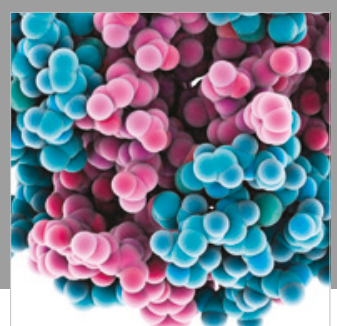

ournal of

Diabetes Research

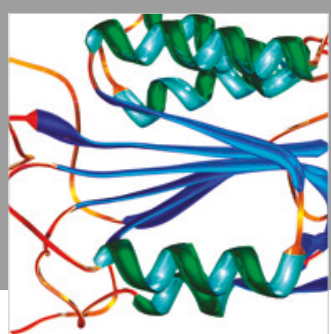

Disease Markers
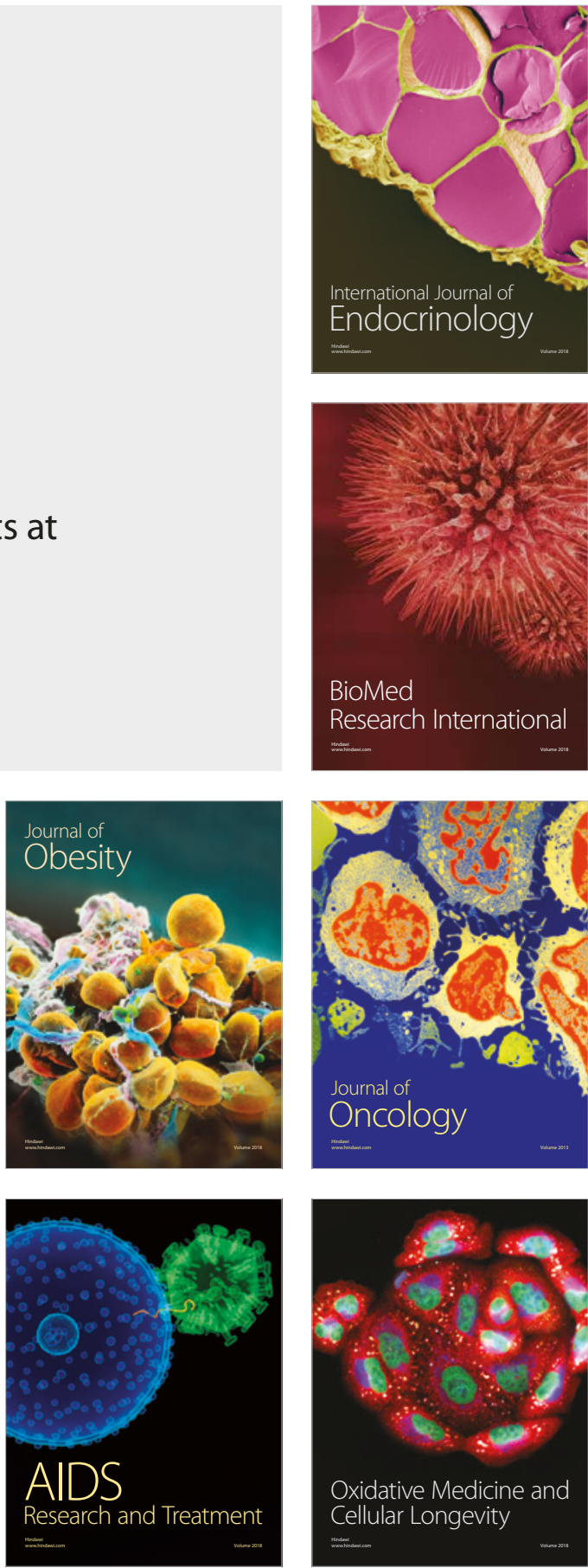